Eduard Lohse

Göttingen

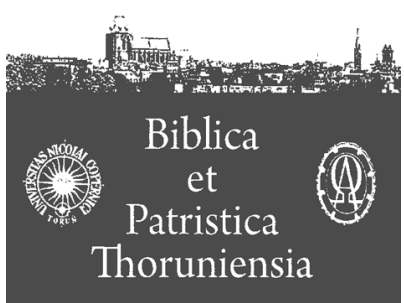

$3(2010)$

\title{
Herrenworte im Römerbrief des Apostels Paulus
}

1. In seinem Schreiben, das er an die Christen in Rom gerichtet hat, erwähnt der Apostel Paulus weder Jesu Verkündigung von der anbrechenden Herrschaft Gottes noch seine Taten und Wunder ${ }^{1}$. Doch er hebt mit Deutlichkeit hervor, dass Jesus Christus gekreuzigt und aus dem Tod auferweckt wurde $(8,34)$. Damit bezieht Paulus sich auf das gemeinchristliche Bekenntnis, wie es in der Verkündigung des Evangeliums ausgelegt wurde. Der Inhalt dieser Botschaft, wie sie schon in den ersten, bereits vorpaulinischen Gemeinden geglaubt und verkündigt wurde, ist bezogen auf die Verheißungen Gottes, wie sie von den Propheten Israels ausgesprochen worden waren, und hebt nun hervor, dass diese Verheißungen in Christus Jesus erfüllt sind. Denn die gute Nachricht des Evangeliums handelt von Sohn Gottes, „der geboren ist aus dem Geschlecht Davids nach dem Fleisch, und nach dem Geist, der heiligt, eingesetzt ist als Sohn Gottes in Kraft durch die Auferstehung von den Toten" (1,3 f.). Gott hat seine Barmherzigkeit offenbart, ,indem er auch seinen eigenen Sohn nicht verschont, sondern ihn für uns alle dahingegeben hat" $(8,32)$. Alle, die auf diese Botschaft vertrauen, sollen gerettet werden. Denn Gott will uns alles schenken in Christus. Christen sind daher überzeugt, dass nichts „uns scheiden kann vor der Liebe Gottes, die in Christus Jesus ist, unserm Herrn" $(8,39)$.

Wenn Paulus diesen zentralen Inhalt des Evangeliums hervorhebt, bleibt er sich stets dessen bewusst, dass Christus nach dem Fleisch aus Israel kam $(9,5)$. Bezeichnet ihn der Apostel als Kyrios, so blickt er dabei ebenso auf das irdische Wirken Jesu wie auch auf den erhöhten Herrn. Den Titel „Herr” wendet er sowohl auf den erniedrigten Christus wie auch auf den erhöhten Herrn an, ohne dabei einen Unterschied zu machen. Wenn der Apostel daher gelegentlich ein Wort Jesu Christi zitiert, bezeichnet er ihn stets als Kyrios (1. Kor. 7,10.12; 9,14; 11,23; 1. Thess. 4,15). Das bedeutet, dass nach dem Verständnis des Paulus Jesus

1 Es könnte freilich zwei Ausnahmen geben: 1. wenn das Gebet „Abba/Vater” $(8,15)$ dahin verstanden werden könnte, dass es auf das Herrengebet verweist, und 2. wenn die Bezugnahme auf das „Reich Gottes” einen zentralen Begriff aus der Verkündigung Jesu aufnimmt. Cf. G. Haufe, Reich Gottes bei Paulus und in der Jesustradition, NTS 31 (1985), 467-372. 
Christus ebenso im Blick auf sein irdisches Wirken wie auch als der erhöhte Herr als „Kyrios” bekannt wird. Eben dieser Herr hat zum Apostel gesagt: „Lass dir an meiner Gnade genügen; denn meine Kraft ist in den Schwachen mächtig" (2. Kor. 12,9).

2. In seinen Briefen, die er an die Gemeinde in Korinth geschrieben hat, bezieht sich Paulus - wie eben bereits erwähnt - mehrmals auf ein Wort Jesu. Dabei betont er, dass auf Grund eines Wortes des Herrn ethische Fragen, die in der Gemeinde gestellt werden, verbindlich entschieden werden können. In seinem nach Rom gerichteten Brief aber führt der Apostel an keiner Stelle ein Herrenwort an, das er als solches kenntlich gemacht hätte. Im letzten Hauptteil seines Schreibens entfaltet er in ausführlichen Gedankengängen Grundzüge einer christlichen Ethik. Doch nirgendwo weist er darauf hin, dass Christen den ausdrücklichen Weisungen des Herrn in ihrem sittlichen Verhalten zu folgen haben. Der Leser könnte daher das Empfinden haben, dass im Römerbrief überhaupt keine Herrenworte zitiert werden. Trifft aber dieser Eindruck zu? ${ }^{2}$

Die vielen ethischen Anweisungen (12,1-15,13) sind vom Apostel unter die Überschrift gestellt, dass Christen „sich nicht dieser Welt gleich stellen, sondern sich durch Erneuerung ihres Sinnes ändern sollen” $(12,1 \mathrm{f}$.) und dass „ihre Liebe ohne Falsch sein solle” (12,9). Der Begriff „Agape” wird zwar im klassischen Griechisch gelegentlich verwendet, aber nur selten im Zusammenhang ethischer Ausführungen gebraucht. In der urchristlichen Verkündigung aber wird der Begriff der Liebe ins Zentrum der Unterweisung gerückt. Denn allein die Liebe bestimmt sittliche Lebensführung, wie sie Gott gefällt. Daher rückt der Apostel das Liebesgebot an den Anfang seiner ethischen Ausführungen über ein verantwortlich gestaltetes Leben der Christen. Was dieses Leitmotiv im einzelnen bedeutet, wird dann in den folgenden Abschnitten, in denen sowohl alttestamentliche Zitate wie auch urchristliche Bekenntnisformulierungen aufgenommen werden, erläutert ${ }^{3}$. Der aufmerksame Leser wird beobachten,

2 Das Problem „Herrenworte im Römerbrief” ist nicht nur in gelehrten Kommentaren zu Rom. 12, sondern auch in folgenden Studien erörtert worden: H.-W. Kuhn, Der irdische Jesus bei Paulus als traditionsgeschichtliches und theologisches Problem, ZThK 67 (1970), 295-320; P. Stuhlmacher, Jesustradition im Römerbrief, Theol. Beitr. 14 (1983), 240-250; N. Walter, Paulus und die urchristliche Jesustradition, NTS 31 (1985), 498-522; J.D.G. Dunn, Paul's Knowledge of the Jesus Tradition, The Evidence of Romans, in: Festschrift W. Trilling: Christus bezeugen, Freiburg/Basel/Wien: Hender, 1990, 193-207; D. Wenham, Paulus - Jünger Jesu oder Begründer des Christentums?, Paderborn/München/Wien/Zürich: Ferdinand Schöningh 1999 - deutsche Übersetzung des englischen Originals, Cambridge 1995.

3 Vgl. B. Byrne, Romans, Collegeville/Minn: The Liturgical Press 1996, 375: „The content suggests that the passage taps a considerable variety of source material: the prophetic and wisdom traditions of the Old Testament, the Jesus tradition preserved in the early communities, ethical reflections and maxims of popular Greco-Roman philosophy". 
dass in urchristlicher Ethik manche Regeln und Weisungen aufgenommen werden, wie sie in antiker Popularphilosophie formuliert worden waren. Solche Wendungen und Sätze aber werden nun in der christlichen Verkündigung unter die Überschrift des Liebesgebots gestellt, um da zu legen, was dieses zentrale Gebot jeweils konkret bedeutet. In dieser Unterweisung finden sich aber auch einzelne Sätze, die weder aus der hellenistischen Umwelt noch aus dem zeitgenössischen Judentum aufgenommen werden, sondern entfalten, was die frohe Botschaft des Evangeliums für die Glaubenden zu sagen hat. So will auch die ethische Unterweisung des Römerbriefs dahin verstanden werden, wie „imitatio Christi” im konkreten Lebensvollzug zu gestalten ist.

3. In den weit ausgreifenden Ausführungen, in denen der Apostel seine ethische Unterweisung darlegt, finden sich nun einzelne Sätze, die ihrem Inhalt nach sehr nahe bei Aussagen aus der Verkündigung Jesu stehen. So heißt es: „Segnet, die euch verfolgen; segnet und flucht nicht” $(12,14)$. Jünger Jesu mussten die bittere Erfahrung machen, dass man sie abwies und verfolgte. Darauf suchte sie ihr Herr vorzubereiten, indem er sagte: „Liebt eure Feinde; tut wohl denen, die euch hassen; segnet, die euch verfluchen; betet für die, die euch verfolgen" (Luk. 6,27 f.). Die Parallele im Matthäusevangelium lautet so: „Liebt eure Feinde, und betet für die, die euch verfolgen" (Matth. 5,44).

Als Paulus seinen Brief an die Christen in Rom schrieb, gab es noch keinen schriftlichen Bericht über Jesu Worte und Taten. Die Bücher, die wir „Evangelien” nennen, sind nach der Zeit des Apostels geschrieben worden. Gleichwohl ist deutlich zu erkennen, dass Paulus auf ein Herrenwort anspielt. Verkündigung Jesu ist insbesondere im Blick auf ethische Fragen überliefert worden. Seine sittlichen Weisungen wurden von den frühen Christen mündlich bewahrt und weitergegeben. Der Wortlaut dieser Sätze war nicht auf eine einzige bestimmte Gestalt festgelegt. Aber bestimmte Autorität wurde der Weisung Jesu beigelegt: Liebt eure Feinde. Vergleicht man den Wortlaut dieser autoritativen Anweisung, wie sie in den verschiedenen Texten, die dieses Gebot weitergeben, formuliert worden ist, so tritt deutlich hervor, dass Jesu Wort als bindende und in Pflicht nehmende Regel inhaltlich zutreffend tradiert worden ist.

Zum Liebesgebot gibt es weder in der jüdischen noch in der griechischen Tradition vergleichbare Parallelen ${ }^{4}$. Daher darf gefolgert werden, dass in diesem Satz ein authentisches Wort Jesu vorliegt. Paulus hebt jedoch nicht hervor, dass es sich hier um ein Jesuswort handelt. Ähnlich verhält es sich bei alttestamentlichen

4 Cf. D. Moo, The Epistle to the Romans, Grand Rapids, Mich. Cambridge UK: William B. Erdmanns Publishing Company 1996, 781: „It was Jesus himself who first accentuated this demand of the kingdom, and there is good reason to think that Paul deliberately alludes to Jesus' own saying". 
Zitaten in den Briefen des Apostels. Manchmal leitet Paulus ein solches Zitat mit einem ausdrücklichen Hinweis ein, dass es sich um ein Wort der Schrift handelt; des öfteren aber fehlt eine solche Einleitung und wird das biblische Wort unmittelbar in die Gedankenfolge eingefügt. Der Apostel ist sich dessen bewusst, dass seine Hörer und Leser gleichwohl die Intention des zitierten Satzes - wie z. B. in den hymnisch gefassten Sätzen am Ende von Römer 11 (V. 34 f.). In vergleichbarer Weise verfährt Paulus, wenn er sich auf Worte Jesu bezieht. Man mag freilich fragen, ob alle Glieder der Gemeinde wahrnehmen konnten, wo und wie ein Herrenwort zur Begründung ethischer Weisungen angeführt ist - und wo nicht (cf. 1. Kor. 7,10.12). Doch darf man annehmen, dass Christen, die eine gründliche Unterweisung über die Inhalte des Evangeliums erhalten hatten, in der Lage waren zu verstehen, wo und wann der Apostel sich auf einen biblischen Satz oder ein Herrenwort berief.

4. Aus dem Kontext in Röm. 12 wird ersichtlich, welche Bedeutung der Anspielung auf ein Herrenwort in V. 14 zukommt $^{5}$. Denn im weiteren Gedankengang nimmt der Apostel eine andere Weisung auf, die für die Christen bindend ist: „Vergeltet niemandem Böses mit Bösem” (V. 17). Kundige Hörer und Leser des Apostels werden auch hier imstande gewesen sein zu erkennen, dass Paulus erneut ein mündlich überliefertes Herrenwort aufgreift. Denn die Weisung, nicht Böses mit Bösem zu vergelten, ist ein ausgesprochen christlicher Satz, zu dem es in der alten Welt keine vergleichbaren Parallelen gibt ${ }^{6}$.

Paulus führt hier ein Herrenwort an, zu dem Luk. 6,29.35 zu vergleichen ist: „Und wer dich auf die eine Backe schlägt, dem biete auch die andere dar [...]. Liebt eure Feinde; tut Gutes und leiht, wo ihr nichts dafür zu bekommen hofft". Beim Evangelisten Matthäus lautet diese Weisung so: „Widersteht nicht dem Übel, sondern: Wenn dich jemand auf die rechte Backe schlägt, dem biete auch die andere dar... Liebt eure Feinde und betet für die, die euch verfolgen" (Matth. $5,38 \mathrm{f}$. und $43 \mathrm{f}$. $)^{7}$.

Die Betrachtung von Röm. 12,17 ergibt denselben Befund wie zu V. 14. Nicht an einem wortwörtlich übereinstimmenden Satz ist zu erkennen, dass das Zitat eines Herrenwortes vorliegt. Sondern in inhaltlicher Hinsicht stimmen die vergleichbaren Worte überein. Die zentrale Bedeutung der Botschaft Jesu ist sowohl in den Evangelien wie auch bei Paulus unterstrichen: Vergeltung wird

5 Cf. C.E.B. Cranfield, The Epistle to the Romans II, Edinburgh: T. \& T. Clark 1979, 640: „We have here a free reminiscence of the traditional dominical saying".

6 Cf. J.A. Fitzmyer, Romans, New York/London: Doubleday 1993, 656 formuliert behutsam: „Paul's counsel of no retribution May echo the words of Jesus”.

7 Cf. Auch Matth. 5,9: „Seilig sind die Friedensstifter; denn sie werden Gottes Kinder heißen". 
strikt untersagt ${ }^{8}$. Paulus greift auf mündliche Tradition zurück, die noch nicht schriftlich festgehalten ist, aber doch eine deutlich erkennbare Gestalt ethischer Unterweisung darstellt.

Im Fortgang seiner die Ethik betreffenden Ausführungen wiederholt Paulus in V. 19f. noch einmal, dass Christen sich nicht selbst an anderen rächen sollen. „Denn es ist geschrieben: Die Rache ist mein, ich will vergelten, spricht der Herr" (vgl. Deut. 32,31 und Prov. 25,21)9. An dieser Stelle macht Paulus ausdrücklich darauf aufmerksam, dass er ein Schriftzitat bringt. Es soll dazu dienen, um den autoritativen Charakter des Gebotes zu begründen, das in voller Übereinstimmung mir der Verkündigung Jesu betont wird ${ }^{10}$.

5. Es ist wichtig zu beachten, dass die Sätze, in denen in Röm. 12 Herrenworte zitiert werden, bei den Synoptikern ihre Parallelen in der Bergpredigt (Matth. 5-7) bzw. in der Feldrede (Luk. 6, 20-49) haben ${ }^{11}$. Daran ist zu erkennen, dass es schon eine mehr oder weniger fest geprägte Tradition von Herrenworten gegeben hat, ehe die Evangelisten ihre Berichte über Jesu Taten und Worte niederschrieben. Mit hoher Wahrscheinlichkeit kann angenommen werden, dass dem Apostel Paulus bereits eine fester gefügte Zusammenstellung mündlich überlieferter Herrenworte bekannt gewesen sein wird. Wir können nicht sagen, ob Paulus außer der hier erkennbaren Tradition auch andere Überlieferungsstücke aus der Verkündigung gekannt haben mag. Denn er gibt nirgendwo einen Hinweis auf weitere mündlich tradierte Stücke der Verkündigung Jesu ${ }^{12}$.

In welcher Weise Herrenworte in urchristliche Unterweisung zu ethischen Fragen aufgenommen wurden, lässt sich auch im Jakobsbrief beobachten ${ }^{13}$. In verschiedenen Versen greift der Verfasser auf Worte Jesu zurück, ohne darauf hinzuweisen, dass es sich um Herrenworte handelt. Wie Jesus seine Jünger

8 Cf. J. Sauer, Traditionsgeschichtliche Erwägungen zu den synoptischen und paulinischen Aussagen über Feindesliebe und Wiedervergeltungsverzicht, ZNW 76 (1985), 1-28. Er weist mit Recht darauf hin, dass man nicht eine vorpaulinische schriftliche Quelle voraussetzen kann (21). Aber man wird seiner These nicht zustimmen können, dass der paulinische Satz die Vorlage für die später aufgezeichnete synoptische Tradition gewesen könnte (28).

9 Cf. K. Stendahl, Hale, Non- Retaliation and Love, 1 QS X, 17-20 and Rom. 12, 19-21, HThR 55 (1962), 134-149.

10 Cf. Byrne, loc cit. 381: „The contradiction of the lex talionis represents a Pauline form of the teaching of Jesus recorded in Matt. 5, 38-42".

11 Cf. J. D.G. Dunn, Romans 9-16, Dallas: Word Books Publisher 1988, 745: „The Jesus tradition had evidently entered into the living stream of Christian Parenesis".

12 Cf. Die Mahnung zur Vorsicht bei N. Walter, loc cit., $503 \mathrm{f}$.

13 Cf. E. Lohse, Glaube und Werke-zur Teologie des Jakobsbriefes, ZNW 48 (1957), 1-22 = Die Einheit des Neuen Testaments, Göttingen: Vandenhoeck \& Ruprecht 1973, 285-306, bes. $293 \mathrm{f}$. 
anwies: „Ihr sollt überhaupt nicht schwören, weder beim Himmel, denn er ist Gottes Thron; noch bei der Erde, denn sie ist der Schemel seiner Füße... Eure Rede aber sei: Ja, ja; nein, nein. Was darüber ist, das ist vom Übel" (Matth. 5,34-37), so wird auch Jak. 5,12 die Weisung gegeben: „Schwört nicht, weder beim Himmel noch bei der Erde noch mit einem anderen Eid. Es sei aber euer Ja ein Ja und euer Nein ein Nein". Und Matth. 7,7 wird die Verheißung ausgesprochen: „Bittet, so wird euch gegeben; suchet, so werdet ihr finden; klopfet an, so wird euch aufgetan”, Jak. 1,5 lesen wir dazu: „Wenn es aber jemandem unter euch an Weisheit mangelt, so bitte er Gott, der jedermann gern gibt und niemanden schilt; so wird sie ihm gegeben werden". Die Bergpredigt schließt mit der Aufforderung: nicht nur Jesu Worte zu hören, sondern auch zu tun, was sie sagen" (Matth. 7,24-27). Und Jak. 1,22 wird das Gebot ausgesprochen: „Seid aber Täter des Worts und nicht Hörer allein”. Denn sonst würde man sich betrügen.

Es ließen sich weitere Beispiele aufführen, die Parallelen zwischen Versen des Jakobsbriefes und Sätzen in der Bergpredigt enthalten. Aber die aufgeführten Beispiele mögen genügen, um zu zeigen, dass sich in urchristlicher ethischer Unterweisung des öfteren Bezugnahmen auf Herrenworte finden- zumeist ohne ausdrücklich hervorzuheben, dass es sich um Worte Jesu handelt.

Urchristliche sittliche Unterweisung stand unter dem Leitmotiv, „in dem Herrn zu leben". Unter den verschiedenen Überlieferungsstücken, die ethische Weisungen enthielten, finden sich auch Herrenworte, die nicht nur überliefert, sondern auch ausgelegt wurden. Auf diese Weise wurde den frühchristlichen Gemeinden vor Augen gerückt, welche Weisungen sie von ihrem Herrn erhalten hatten. Diese Ermahnungen sollten sie dazu anhalten, den Namen des Herrn $\mathrm{zu}$ ehren und zu preisen, indem sie seinen Geboten gehorsam Folge leisteten. In Röm. 12,9-21 liegt also eine frühe Überlieferung mündlicher Tradition von Herrenworten vor, die das sittliche Verhalten der Christen bestimmen sollten. Später wurden dann größere Zusammenhänge zusammengefügt, wie sie einerseits in der Feldrede beim Evangelisten Lukas und andererseits in der Bergpredigt beim Evangelisten Matthäus vorliegen.

6. Wenn Paulus urchristliche Unterweisung unter das Leitmotiv der Liebe stellt, so folgt er darin der Verkündigung Jesu ${ }^{14}$. Diesen Zusammenhang lässt auch der Abschluss des langen Gedankengangs der Kapitel Röm. 12 und 13 erkennen. Denn der Apostel beendet die vielen Lehrsätze und Weisungen, die die Lebensführung der Christen betreffen, indem er noch einmal die grundsätzliche Bedeutung des Liebesgebots unterstreicht: „Seid niemand etwas schuldig, außer,

14 Cf. Dunn, loc cit., 779: „It must be judged almost certain that Paul is drawing here on the tradition that Jesus himself summed up the law by reference to Lev. 19; 18 ". 
dass ihr euch untereinander liebt. Denn wer den anderen liebt, der hat das Gesetz erfüllt... Denn was da sonst an Geboten ist, das wird in diesem Wort zusammengefasst: Du sollst deinen Nächsten lieben wie dich selbst. Die Liebe tut dem Nächsten nichts Böses. So ist nun die Liebe des Gesetzes Erfüllung" (Röm. 13,8-10).

„Welches ist das höchste Gebot?” Als Jesus diese Frage beantwortete, formulierte er das Doppelgebot der Liebe: Gott zu lieben und den Nächsten wie sich selbst (Mark. 12,28-34 Par.). Ist das erste Gebot des Dekalogs darin verstanden, dass es alle folgenden Gebote einschließt, so bedeutet das zugleich, dass die Liebe zu Gott den Nachbarn nicht übersehen darf. Denn Gott wird die ihm geschuldete Ehre erwiesen, indem wir dem Nächsten in Liebe dienen. In der urchristlichen Unterweisung wurde daher das Liebesgebot, wie Jesus es ausgesprochen hat, in das Zentrum ethischer Weisungen gestellt ${ }^{15}$. Indem der Apostel Paulus dieses Gebot so nachdrücklich unterstreicht, folgt er auch hier einem Wort und Gebot des Herrn, das ihm durch die mündliche Überlieferung vorgegeben war $^{16}$.

Der gewinnenden Kraft der Liebe ist keine Grenze gesetzt. Sie wird weder durch die Überlegung eingeschränkt, ob der Nächste auch dessen wert ist, dass man ihm in Liebe begegnet, noch wird der Kreis derer, denen Liebe zu erweisen ist, eng gefasst. Urchristliche Unterweisung hielt entschieden am Gebot Jesu fest, auch die Feinde zu lieben. Darum wiederholt Paulus am Schluss von Röm. 13 noch einmal die Weisung, die in Röm. 12,14 ausgesprochen wurde: "Segnet, die euch verfolgen; segnet und flucht nicht" ${ }^{17}$. Das bedeutet, dass ohne Einschränkung die Verpflichtung gilt: „Die Liebe tut dem Nächsten nichts Böses" (Röm. 13,10).

Was das Liebesgebot jeweils in konkreter Situation fordert, wird nicht in kasuistischen Erwägungen im Voraus festgelegt. Denn die Liebe wird als bestimmendes Leitmotiv für jedes Handeln der Christen verstanden und hat sich daher jeweils an den konkreten Möglichkeiten und Gegebenheiten zu orientieren. Ist die Liebe die Erfüllung des Gesetzes, so sind alle Gebote in dem Sinn verstanden, dass die Liebe darüber entscheidet, was in der jeweiligen konkreten Situation zu tun oder auch zu unterlassen ist. Weil die Liebe Gottes Gebot für jede Situation und jede Zeit ist, gilt sie immer und an jedem Ort.

15 Cf. V. Furnish, The Love Command in the New Testament, Nashville: Abingdon 1972; Th. Söding, Das Liebesgebot bei Paulus. Die Mahnung zur Agape in Rahmen der paulinischen Ethik, NTA NF 26, Münster: Aschendorff 1995.

16 Cf. R. Jewett, Romans, Minneapolis: Fortress Press 2007, 813: as say „likely that Paul is following a tradition established by Jesus, who gave unique importance to the law of Love".

17 Cf. 1. Petr. 3,9: „Vergeltet nicht Böses mit Bösem oder Scheltwort mit Scheltwort, sondern segnet vielmehr, weil ihr dazu berufen seid, dass ihr den Segen ererbt”. 
Die Liebe erweist darum ihre kritische und bestimmende Kraft, indem sie vorgegebene ethische Regeln prüft und entscheidet, auf welche Weise sie angesichts neuer Herausforderungen zu handeln hat.

Fassen wir zusammen, was sich über Herrenworte, wie Paulus sie im Römerbrief aufnimmt, sagen lässt, so kann festgestellt werden, dass der Apostel mündlich überlieferte Sätze aus der Verkündigung Jesu aufnimmt. Er hebt nicht hervor, dass er hier oder dort ein Wort des Herrn zitieren will. Er verwendet jedoch einzelne Herrenworte in derselben Weise, wie er sich an vielen Stellen auf alttestamentliche Sätze bezieht. Indem er vorgegebene Worte und Weisungen in seine ethischen Ausführungen einfügt, nimmt er auch einzelne Herrenworte auf. Alle sittlichen Gebote aber werden unter die Überschrift des Liebesgebots gebracht und auf diese Weise zusammengefasst. Denn dieses schlechthin bestimmende Gebot will von allen Christen, die ihrem Herrn gehorsam sein wollen, zu jeder Zeit befolgt werden.

Spricht Paulus von der Autorität des Kyrios, so macht er keine Unterscheidung zwischen dem historischen Jesus und dem erhöhten Herrn. Sagt er, er sei im Herrn Jesus fest überzeugt, „dass nichts unrein ist an sich selbst, sondern nur für den, der es für unrein hält, sei es unrein" (Röm. 14,14), so drückt er seine Überzeugung aus, wie Christen unter der Herrschaft Christi Jesu zu leben haben. Dabei ist jedoch deutlich zu erkennen, dass der Inhalt dieses Satzes vollauf mir der Unterscheidung übereinstimmt, die Jesus über Rein und Unrein getroffen hat (Mark. 7,1-23 Par.) ${ }^{18}$.

Sittliche Unterweisung, wie sie in den frühen urchristlichen Gemeinden formuliert wurde, kann sich hier und da an Herrenworten orientieren, die in der mündlichen Tradition bewahrt und weitergegeben wurden. Sie kann aber auch in kritischer Prüfung überkommener Lehre und Weisheit bei Juden und Griechen entscheiden, was die Liebe jeweils zu gebieten hat. Das aber bedeutet, dass Christen ihr Leben zu gestalten haben, „einander anzunehmen haben, wie Christus sie angenommen hat” (Röm. 15,7); denn sie sollen „einträchtig gesinnt sein untereinander, Christus Jesus gemäß” (Röm. 15,5). „Christus Jesus gemäß” zu leben bedeutet nichts anderes als „nach der Liebe zu leben” (Röm. 14,15). Wo immer jemand einen anderen höher achtet als sich selbst und darauf bedacht ist, dem anderen zu dienen, da wird Gottes Wille befolgt und das Gesetz Christi erfüllt (Gal. 6,2).

18 Cf. Jewett, loc. cit. 859: „It seems quite likely that the clause 'nothing is unclean in itself' is a citation from the dominical tradition". 


\section{Słowa Pana w Liście św. Pawła Apostoła do Rzymian}

\section{Streszczenie}

W liście do wspólnoty chrześcijan w Rzymie św. Paweł Apostoł nie wymienia ani przepowiadania Jezusa Chrystusa o nadchodzącym Królestwie Bożym, ani też Jego czynów i cudów. W centrum przesłania listu pozostaje jednak Chrystus ukrzyżowany i zmartwychwstały $(8,34)$, Ten, który wypełnił obietnice Boga, zapowiedziane przez proroków Izraela „o Jego Synu - pochodzącym według ciała z rodu Dawida, a ustanowionym według Ducha Świętości przez powstanie z martwych pełnym mocy Synem Bożym” (1,3n.). Termin „Kyrios”, którym posługuje się św. Paweł, odnosi się więc zarówno do Jezusa historycznego, jak i wyniesionego do chwały przez Boga Ojca.

W swoim nauczaniu moralnym Apostoł wielokrotnie nawiązuje do słów Jezusa, lecz odzwierciedla wyłącznie ich sens, tj. nie cytuje w sposób dosłowny. Podejmuje tym samym tradycję ustną Chrystusowego przepowiadania, która spisana została przez Ewangelistów dopiero w późniejszym czasie. W podobny sposób cytuje on pisma Starego Testamentu, ufając, iż jego czytelnicy i słuchacze uchwycą sens i intencje tych słów. Można zatem przyjąć, iż chrześcijanie, którzy uprzednio otrzymali gruntowną naukę o Dobrej Nowinie, z pewnością potrafili zrozumieć wszelkie sugestie i nawiązania Apostoła do ksiąg biblijnych i słów Pana, nawet jeśli nie zostały one wyraźnie wprowadzone przez odpowiednie konstrukcje językowe.

W Liście do Rzymian Apostoł odnosi się do etyki życia, do „agape”, która znana była wprawdzie w świecie greckim i żydowskim, ale dopiero w perspektywie chrześcijańskiej otrzymała miejsce centralne w nauczaniu moralnym. Przykazanie miłości, przywołane w Rz 12,9-21, wynika zatem z przepowiadania Chrystusa (por. Mt 5,38n. i 43n.; Łk 6,29.35) i w znaczący sposób determinuje życie chrześcijan, bowiem pozostaje nadrzędnym wobec wszystkich innych przykazań i motywuje do naśladowania Pana. „Imitatio Christi” oznacza zatem nic innego, jak „postępowanie zgodnie z miłością” (Rz 14,15), tj. szacunek i służbę drugiemu człowiekowi, przez co wypełnia się wolę Bożą i prawo Chrystusowe (por. Ga 6,2).

Słowa Pana, zaakcentowane w Liście do Rzymian i podważające celowość odwetu (por. 12,17 i 12,14), mają swoją paralelę m.in. w Kazaniu na Górze (Mt 5-7) i na Równinie (Łk 6,20-49), istniejących pierwotnie i przekazywanych $w$ tradycji ustnej. Wczesnochrześcijańskie nauczanie moralne, takie jak u św. Pawła, inspirowane było dlatego w szczególności „nowym życiem w Panu”, 
tj. słowem samego Chrystusa. Przykazanie miłości, które z woli Boga obowiązuje zawsze i wszędzie, nie może być wobec tego ujęte w ramy kazuistycznych rozważań dotyczących warunków jego realizacji. Miłość jest bowiem niczym nieograniczona, punktem odniesienia dla każdego czynu chrześcijanina, który realizowany jest zgodnie z możliwościami i okolicznościami danej sytuacji. „Miłość jest doskonałym wypełnieniem Prawa” (Rz 13,10).

\section{The words of the Lord in the Letter to the Romans}

\section{Summary}

In his teaching on morality Paul many times refers to the words of Jesus, but instead of quoting them directly he simply renders their meaning. In the Letter to the Romans Paul deals with the ethics of Christian life and in this context Jesus' words are also mentioned. Lohse studies different aspects of early Christian moral teaching arguing that it was mostly inspired by words of Jesus as remembered and transmitted by the early Church. 